COMECHINGONIA. REVISTA DE ARQUEOLOGÍA

Número 14, 2011, pp. 173-189, Córdoba

ISSN 0326-7911

\title{
SAN JOSÉ DE FLORES UN LUGAR EN EL MUNDO
}

\author{
Ulises Camino \\ CAU-FADU- UBA. CONICET. Pabellón III $4^{\circ}$ Piso Ciudad Universitaria. CABA \\ ulisescamino@yahoo.com.ar
}

Presentado el: 8/11/2010 - Aceptado 16/03/2011

\begin{abstract}
Resumen
En este trabajo se sintetizan las tareas realizadas por el Proyecto Arqueológico Flores, de la Facultad de Filosofía y Letras de la Universidad de Buenos Aires, hasta el momento. Las hipótesis que guían la investigación, la metodología empleada, la bibliografía relevada, los sitios arqueológicos excavados y el marco teórico utilizado se resume en las siguientes páginas. Se plantea además que la teoría y la metodología aquí empleada puede ser útil para analizar otras regiones urbanas de nuestro país y Latinoamérica.
\end{abstract}

Palabras claves: San José de Flores, Urbanismo, Teoría, Metodología

\section{Abstract}

This paper summarizes the work done by the Archaeological Project Flores, Faculty of Arts at the University of Buenos Aires, so far. The hypothesis that guide the research methodology, the literature surveyed, excavated archaeological sites and the theory used are summarized in the following pages. It also claims that the theory and methodology proposed here can be used to analyze other urban regions of our country and Latin America.

Keywords: San José de Flores, Urbanism, Theory, Methodology.

\section{Introducción}

El objetivo específico del proyecto "Arqueológico San José de Flores" es comprender el desarrollo urbano - económico del otrora pueblo del mismo nombre, ubicado en las afueras de la ciudad de Buenos Aires. En la actualidad, es un barrio de dicha urbe. Principalmente se trata de indagar en las razones de su ubicación geográfica, de qué manera esto se relaciona con los recursos naturales presentes en la zona, con las rutas comerciales del antiguo Virreinato del Río de La Plata y con las políticas económicas del Estado de Buenos Aires y posteriormente con el Estado Nación Argentina. Esto es realizado mediante el estudio de excavaciones arqueológicas en distintos puntos del barrio porteño y del análisis de fuentes documentales. 
En el año 2004 se plantea que la ubicación del pueblo de San José de Flores es estratégica por encontrarse a la vera del Camino Real y a una legua del "Camino de Gauna", ambas fueron las principales rutas de comunicación del puerto de Buenos Aires con el Interior (Mercuri et. al 2004a). En ese mismo trabajo se explora la posibilidad de que los cambios observados en el registro arqueológico para la segunda mitad del siglo XIX sean consecuencia de la consolidación del pueblo por la llegada del ferrocarril y luego del tranway (Mercuri et. al. 2004a).

Por lo tanto nuestros trabajo en el área tiene como hipótesis principal que el crecimiento demografico y de infraestructura edilicia del Pueblo de San José de Flores se debió a su ubicación estratégica, a la vera del camino Real y a pocas leguas del Camino de Gauna, las dos principales rutas que comunicaban el puerto de Buenos Aires con el Interior. Caminos que estaban a su vez enmarcados dentro de los dos cursos de aguas más importantes de la actual ciudad de Buenos Aires, el Riachuelo y el Arrollo Maldonado (Mercuri et al 2004a, Camino y Mercuri, 2005). Estas tierras eran excelentes para la producción agrícola y ganadera (Ciliberto 2004).

Como hipótesis secundaria se propone que el aspecto fundamental que permitió la consolidación del pueblo de San José de Flores, fueron los nuevos medios de transporte, el ferrocarril y el tranway. Ya que estos acortaron los tiempos de traslado de personas y mercaderías desde y hacia la ciudad de Buenos Aires.

\section{Teoría utilizada}

Para poder poner a prueba las hipótesis anteriormente expresadas es necesario utilizar una teoría adecuada, partiendo del supuesto que San José de Flores es parte de un sistema complejo, la economía mundial. Estos tienen como proceso estructurador fundamental la capacidad de autoorganización y de la emergencia del orden a través de transiciones inestables (McGlade 1999). La emergencia, entendida como la capacidad del sistema de ser más que la suma de sus partes, yace en la base de todos los sistemas sociales humanos, como un principio básico para la autoorganización (López Borgoñoz 1999). Un enfoque coherente con la teoría de sistemas complejos es la tesis de autores como Adré Gunder Frank y Barry K. Gills (1993), según la cual todas las sociedades a partir de cierta complejidad (multidimensionales, multireferenciales, multifactoriales), juegan un mismo juego, son una sola sociedad, determinada por la existencia de un único sistema mundial, con diferentes estrategias que van convergiendo a medida que crece la complejidad del sistema global y se interactúa de manera más grande con otras sociedades. Esta teoría es comúnmente denominada Sistema Mundial (Wallerstein 1988).

La propuesta de sistema mundial se asienta en uno de los presupuestos o tesis que proponen una evolución del capitalismo en el que el imperialismo se constituirá en su culminación o máxima representación. Esta posición ha sido para el marxismo del siglo XX una constante. El imperialismo, como fase superior del capitalismo es un concepto acuñado por Lenin (2006), quien también utilizó los términos centro y periferia como conceptos para analizar la economía y la política internacional.

Wallerstein (1974), es el primero en desarrollar la teoría del sistema mundial, éste lo caracteriza como una serie de mecanismos que redistribuyen los recursos desde la periferia 
al centro del sistema. Este mecanismo se puede simplificar esquemáticamente en las relaciones: Centro- semiperiferia- periferia.

Wallerstein escribe que el análisis que permite la teoría del sistema mundial ofrece un valor heurístico - una vía intermedia- entre las generalizaciones históricas y las narraciones particulares. Sostiene que el método óptimo debe perseguir el análisis dentro de las estructuras sistémicas, durante el tiempo y el espacio suficiente para comprender las lógicas que dominan; lógicas que determinan las secuencias más fuertes de la realidad, mientras que a la vez reconoce y considera que estas estructuras sistémicas tienen principio y fin y no deben por lo tanto concebirse como fenómenos eterno.

Si sólo hay un sistema mundial (Frank y Gills 1993), entonces el desarrollo en un estado "nacional" solo puede traer una mejora temporal de una región o de un pueblo dentro del sistema. Y en tal caso, sin duda, el mismo término "desarrollo" tiene poco sentido; sólo lo tendría si se refiere a desarrollo del propio sistema mundial completo, y no sólo a una parte de él.

El marco de la teoría de lo Sistema Mundial es aplicable al caso de estudio porque nos permite modelar la evolución del desarrollo de San José de Flores como consecuencia de su inserción en distintos niveles jerárquicos de desarrollo económico y social. Ordenados según inclusividad son:

$1^{\circ}$ En su relación con Buenos Aires; como núcleo principal del Comercio del Cono Sur.

$2^{\circ}$ En su relación con los distintos centros capitalistas

$3^{\circ}$ En su relación con todo el sistema mundo

Entonces los desarrollos de San José de Flores pueden ser explicables por las dinámicas en cada uno de estos niveles.

\section{Metodología}

Se utilizan fuentes escritas y gráficas (ambas pueden ser primarias o secundarias) que nos permiten desarrollar estrategias de investigación en el registro arqueológico. Tanto las fuentes primarias y secundarias como el registro arqueológico nos permitirán poner a prueba nuestras hipótesis.

Para esto se consultan toda la bibliografía histórica sobre San José de Flores escrita hasta el momento, los documentos escritos y gráficos presentes en el Archivo Histórico de la Ciudad de Buenos Aires y los del Archivo General de la Nación en relación a dicho pueblo. Y se realizan excavaciones arqueológicas en varios puntos del antiguo partido de San José de Flores sobre todo en espacios de dominio público y con los que se contaban con referencias históricas, con el objetivo de poder encontrar un registro material que nos permita poner a prueba nuestras hipótesis.

En cada predio excavado se debió emplear estrategias diferenciales, en algunos casos se debió recurrir a excavaciones de rescate ya que en el lugar se estaban realizando obras que destruirían el registro arqueológico además de imponernos restricciones de espacio y tiempo. En los casos en que fue posible se realizo excavaciones sin restricciones de tiempo y espacio; 
en cuanto a los estratos excavados en algunos casos se pueden vincular a la habitación del lugar y en otros responden a rellenos que provenían de lugares más alejados.

\section{Tareas que se han realizado hasta el momento}

Se ha realizado una búsqueda pormenorizada de fuentes secundarias y se ha comenzado con el análisis de fuentes primarias. Y con estas fuentes se ha procedido a una buena reconstrucción del pasado histórico de Flores.

\section{Reconstrucción histórica}

El 4 de junio de 1588 se completaron los repartos de fracciones en los entonces denominados pagos de la Matanza. Estos pagos ocupaban lo que actualmente son los barrios porteños de Almagro, Caballito, Parque Chacabuco, Nueva Pompeya, Villa Soldati, Flores, Floresta, Velez Sarsfield, Villa Santa Rita, Villa Devoto, Versalles, Lugano, Liniers, Villa Riachuelo, Villa del Parque, Monte Castro y Mataderos y los actuales partidos bonaerenses de La Matanza, Morón y Merlo.

Hacia 1609, el señor Mateo Leal de Ayala, un ganadero proveniente de Perú, quien llegó a ejercer el gobierno de Buenos Aires y además formara parte de una compleja red de contrabando con relaciones en el Alto Perú y Brasil (Garvich, 1988), compró las tierras que más tarde conformarían el casco del pueblo. Luego de diversas herencias, adquisiciones y ventas, Don Juan Diego Flores adquirió las tierras en 1776 (en el mismo año que se crea el Virreinato del Rio de la Plata) y hacia 1800 la chacra abarcaba desde el Riachuelo hasta la chacra de los Colegiales y desde Miserere hasta Ramos Mejía. Su extensión excedía, en mucho, a la Merced original.

El desarrollo demográfico-mercantil de Buenos Aires gracias a convertirse en la capital del nuevo Virreinato y el revitalizador proceso colonizador que lo acompañaba consolidó el valor de estas tierras e impulsó su fraccionamiento. La venta de una porción del terreno al labrador Alberto Fontán, realizada por Juan Diego Flores en 1801, y la donación de varias hectáreas a su administrador Don Antonio Millán marcan el inicio de la parcelación (Ciliberto 2004). Los propietarios habían comenzado a subdividir sus tierras en quintas de no más de 20 hectáreas, en que una considerable cantidad de labradores producían la mayor parte de las frutas y hortalizas que consumía la ciudad y, además, se destacaba la producción de trigo y leña (Ciliberto 2004).

El 31 de Mayo de 1806 se erigió formalmente el curato de San José, en tierras donadas por Don Ramón Francisco Flores (hijo de Juan Diego). Dos años más tarde, Antonio Millán, es designado para el trazado de un pueblo y el terreno se divide en solares junto al Camino Real (actual Avenida Rivadavia), por el que existía un fluido comercio hacia el oeste y el norte del Virreinato (Cunietti-Ferrando 2006). La ubicación del pueblo era estratégica. Atravesado por el Camino Real, se convertía en una parada obligada de carretas y yuntas de bueyes en su viaje entre Buenos Aires y Luján. Otra de las rutas importantes que comunicaban a Flores con la ciudad de Buenos Aires era el llamado Camino de Gauna (actual Avenida Gaona). Las dos vías eran la salida comercial de la provincia y por lo tanto eran una prioridad para los gobiernos provinciales (Pisano 1976). 
El 1 de Diciembre de 1811, el Cabildo de Buenos Aires declaró al pueblo de San José de Flores como Partido, separándolo de los pagos de la Matanza (Cunietti-Ferrando 1977).

Geográficamente el área que ocupaba era intermedia, es decir, una meseta, en este caso cruzada por los arroyos Maldonado y Cildañez, en la cual el material sedimentario sólido que llega traído por la corriente y el material que egresa mantienen un equilibrio. Como no existe erosión visible y hay un buen drenaje, se generan los mejores suelos para el cultivo de flores, hortalizas y frutales (Ciliberto 2004). Esta posición es la que en principio permitió el crecimiento demográfico y económico del naciente pueblo. Convertido en punto de concentración a la vera del Camino Real de la producción procedente de las distintas partes de la campaña, Flores vivía al ritmo de las carretas que arribaban del norte y de la pampa cargadas de cueros, lanas, granos, sebos, yerbas y textiles (Ciliberto 2004) y el poblado crecía a pasos acelerados.

Con la llegada del ferrocarril en 1857, familias patricias de la ciudad de Buenos Aires, construyeron allí sus casas de recreo. Lo característico y único de estas construcciones es que poseían galerías dirigidas hacia las vías ferroviarias (Cunietti-Ferrando 1977).

En 1871 se había construido la primera línea de tranvías desde Plaza Victoria (actual Plaza de Mayo) a la plaza del pueblo de Flores (Cunietti-Ferrando 1977).

En 1880, la ciudad de Buenos Aires es declarada Capital de la República Argentina, separándola de la provincia homónima. De esta manera, San José de Flores, como Partido, siguió dependiendo de las autoridades provinciales. Pero no por mucho tiempo. En 1888, Flores, junto con el barrio porteño de Belgrano, fue anexado a la Capital Federal, y de esta manera continuó el proceso de expansión demográfica y comercial promovido con la llegada del ferrocarril y el tranvía.

Los trabajos arqueológicos hasta el momento se han excavado 6 solares dentro del antiguo partido de San José de Flores (ver figura 1) a saber: Nazca 313, Plaza Pueyrredón, Corralón de Floresta, La Moyosa, Rodriguez-Visillac y Sanatorium Flores. En cada uno de ellos ha sido rescatado abundantes restos arqueológicos. Hasta el momento fueron procesados y cuantificados los sitios: Nazca 313, Plaza Pueyrredón, Corralón Floresta y La Moyosa. Rodriguez-Visillac sólo en forma parcial y el Sanatorium Flores aún no se comenzo su análisis, por lo cual a qui no sera tenido en cuenta. En la Tabla 1 se resumen las superficies, profundidades y cantidades de materiales procesados.

Los restos arqueológicos recuperados pertenecen tanto a la vida cotidiana de Flores como de la ciudad de Buenos Aires, ya que los descartes de la gran ciudad muchas veces tenían

\begin{tabular}{|l|c|c|c|c|}
\hline Predio & $\begin{array}{l}\text { Superficie } \\
\text { intervenida }\end{array}$ & $\begin{array}{l}\text { profundidad } \\
\text { maxima }\end{array}$ & $\begin{array}{l}\text { potencialidad } \\
\text { arqueological } \\
\text { máxima }\end{array}$ & $\begin{array}{l}\text { cantidad de } \\
\text { materiales } \\
\text { procesados }\end{array}$ \\
\hline Plaza Pueyrredón & $16 \mathrm{~m} 2$ & $3,50 \mathrm{~m}$ & $3 \mathrm{~m}$ & 5463 \\
\hline Corralón de Floresta & $14 \mathrm{~m} 2$ & $2,30 \mathrm{~m}$ & $2 \mathrm{~m}$ & 4563 \\
\hline Nazca 313 & $2 \mathrm{~m} 2$ & $0,80 \mathrm{~m}$ & $0,60 \mathrm{~m}$ & 769 \\
\hline La moyosa & $6 \mathrm{~m} 2$ & $1,80 \mathrm{~m}$ & $1,50 \mathrm{~m}$ & 878 \\
\hline Rodriguez - Visillas & $12 \mathrm{~m} 2$ & 2,50 & 2,20 & 1200 \\
\hline
\end{tabular}

Tabla 1 


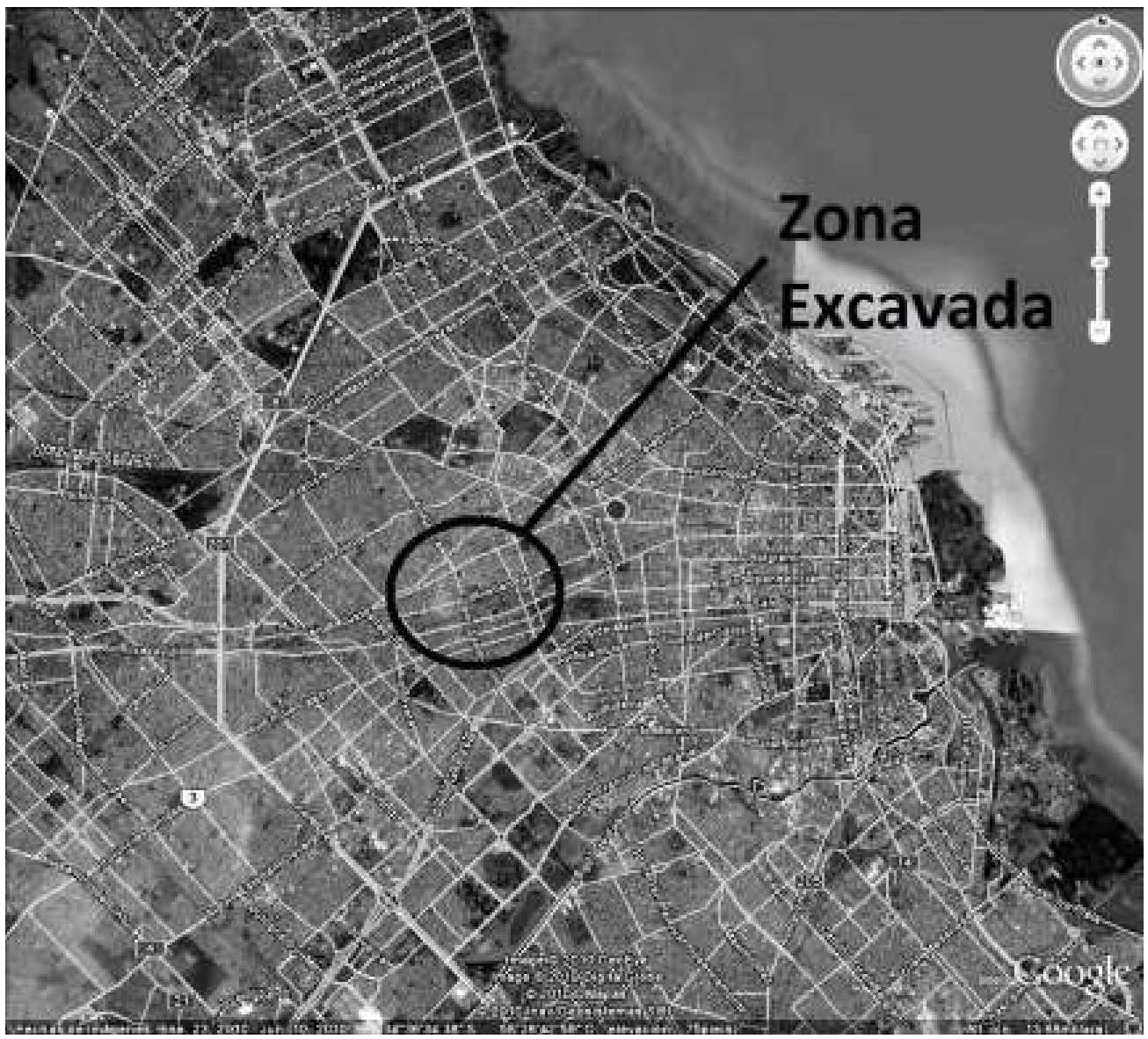

Figura 1 Referencias: 1 Sitio Corralón de Floresta, 2 Sitio Nazca 313, 3 Sitio RodríguezVisillac, 4 Sitio Plaza Pueyrredón, 5 Sitio La Moyosa

como destino final los terrenos inundables del partido de San José de Flores (Camino 2007). Entre los objetos rescatados abundan los artículos industriales de origen extranjero, fundamentalmente británicos y franceses. Como ejemplo, en la excavación del domicilio particular de Nazca 313 fueron rescatados 200 fragmentos de baldosas marca "Pierre Mauarel Aubagne " cerámicas de origen francés (Camino 2004), en la tabla 2 podemos sintetizar los hallazgos producidos en este solar, que gracias a un piso de baldosas podemos fechar con seguridad como anterior a 1909.

En las excavaciones realizadas en la Plaza Pueyrredón (Mercuri et al. 2004b), la metodología desarrollada en el campo se vincula a una estrategia de arqueología de rescate, con sus consecuentes restricciones de tiempo y lugar. Para esto se determinó el planteo de cuadrículas, con el objetivo de obtener material en capa y con un contexto definido. Uno de estos fue la cuadrícula 1 en ella se detecto un estrato con abundantes restos materiales que provenían de lo que vulgarmente se conoció como "la quema", lugar donde se incineraban los residuos de la ciudad de Buenos Aires. Estos materiales eran usados como relleno para nivelar el terreno de la plaza, práctica común realizada por la municipalidad a principios de 


\begin{tabular}{|l|r|}
\hline Vidrios & 10 \\
\hline Lozas & 10 \\
\hline Baldosas & 222 \\
\hline Ladrillos & 6 \\
\hline Litices & 4 \\
\hline Molduras & 4 \\
\hline Metales & 6 \\
\hline Indoro Gres & 3 \\
\hline Oseos & 185 \\
\hline Tejas & 3 \\
\hline
\end{tabular}

Tabla 2

siglo XX (Prignano 1999), redepositándose el descarte originado por los habitantes del centro de la ciudad en terrenos públicos. Además de la Cuadrícula 1 se decidió realizar otra excavación en forma de trinchera en una depresión que se observaba en uno de los jardines paralelos a la calle Artigas. Con la ayuda de los planos de Obras sanitarias del año 1936, se constató la presencia de un pozo de absorción lindante con el depósito del placero al final de una rampa, donde hoy se observa la depresión. Este contexto consistió en el de rellenos con una fecha anterior a 1936, momento en el cual fue segado el pozo, presumiblemente vinculados a la demolición de una edificación cercana (Mercuri et al. 2004a), ya que abundan los materiales de construcción de origen nacional de la década de 1930. Además se desarrollaron trabajos de rescate de materiales en los sectores donde estaban trabajando las maquinas retroexcavadoras. La metodología de recolección consistió en recoger los materiales que se encontraban expuestos en los antiguos caminos del paseo levantados por la retroexcavadora. La recuperación de material se hizo siguiendo un criterio sistemático, obviamente influenciado por la visibilidad (Wadsnider y Camilli, 1992). Estos materiales por sus características como la termo alteración se vinculan con los rellenos provenientes de la quema detectados en la cuadricula 1. En toda la excavación de la plaza el grupo artefactual de mayor frecuencia fue el de vidrios (24\%) seguido por el de Lozas y cerámicas (18\%) ver cuadro 3; en este segundo abundaban las de origen europeo (95\%), en la Tabla 3 podemos ver la totalidad de materiales rescatados.

Desde 2006 se vienen realizando excavaciones arqueológicas en el sitio Corralón de Floresta (Camino 2007). En dicho predio ubico la quinta La Primavera desde 1886 hasta el año 1911 (aunque de este período cronológico no fueron hallados restos materiales de

\begin{tabular}{|l|r|}
\hline Escorla & 171 \\
\hline Porcelanas & 429 \\
\hline Metales & 887 \\
\hline Vidrio & 1324 \\
\hline ceramicas & 34 \\
\hline Lezas & 924 \\
\hline Gres & 55 \\
\hline Caolin & 7 \\
\hline Arulejos & 506 \\
\hline Materiales construccion & 473 \\
\hline baldosas & 53 \\
\hline Liticos & 63 \\
\hline Gseos & 264 \\
\hline Teatiles & 5 \\
\hline maderas & 21 \\
\hline hidrocarburos & 51 \\
\hline otros & 196 \\
\hline
\end{tabular}

Tabla 3 
importancia), anteriormente el terreno era parte de una chacra dedicada al cultivo de trigo y la producción hortícola (Camino 2007). Desde 1914 hasta el 2005 funcionó en el lugar el Corralón Municipal de la Sección Villas. Se utilizaron dos estrategias de trabajo diferentes: por un lado rescate, y por otro excavación sistemática (sin restricciones de tiempo y espacio). Los primeros, fueron realizados en la mitad del predio que linda con la calle Gualeguaychú (al oeste del predio), dado que en ese sector se estaba construyendo el colegio secundario. La excavación sin límites de tiempo fue realizada en la mitad del terreno que limita con la calle Sanabria, dado que en este lugar, por el momento no se realizaba ningún tipo de obra. A partir de estas se pudieron distinguir tres contextos de hallazgo bien diferenciados, uno vinculado con la historia reciente del predio, otro con los rellenos traídos desde la quema luego de la adquisición municipal del terreno y finalmente un contexto antiguo vinculado con la producción agrícola del predio. El contexto del relleno es fácilmente distinguible en la estratigrafía y puede ser fechado fehacientemente dado que se sabe la fecha de realización que es 1911 y a partir de los hallazgos de la misma se refuerza la cronología de finales del siglo XIX y principios del XX (Camino 2009). En la tabla 4 se pueden ver las cantidades de objetos rescatados en el estrato de relleno proveniente de la incineración de residuos.

\begin{tabular}{|l|r|}
\hline Escorla & 450 \\
\hline Porcelanas & 150 \\
\hline Metales & 2458 \\
\hline Vidrio & 1789 \\
\hline Ceramica & 45 \\
\hline Lozas & 1498 \\
\hline Gres & 67 \\
\hline Caolin & 23 \\
\hline Axulejos & 245 \\
\hline Materlales de Construccion & 789 \\
\hline Baldosas & 234 \\
\hline liticos & 1456 \\
\hline Greos & 2678 \\
\hline
\end{tabular}

Tabla 4

Mientras se realizaba las obras a partir de la excavaciones de la maquinaria se rescataron más de 200 herraduras utilizadas para los caballos de tiro utilizados en la recolección de residuos ejemplifica la historia reciente del predio. También en esta situación bajo la base de una antigua columna de un galpón se rescató una placa con el nombre de la compañía constructora, de origen británico (A\&J Main \& $C^{\circ} L^{\circ}$. 1909. Structural Engineers. Glasgow London \& Calcuta).

El contexto más antiguo (anterior a 1911) es un paleosuelo conformado por humus de un espesor de entre 35 y $45 \mathrm{~cm}$, aquí sólo fueron hallados dos fragmentos de loza tipo creamware ( de origen británico), lo que nos muestra la baja densidad artefactual en estos contextos tempranos.

Entre Octubre de 2007 y Enero de 2008 se realizaron excavaciones arqueológicas en la actual plaza La Misericordia. En este terreno se ubicaba hasta mitad del siglo XX la quinta $\mathrm{La}$ Moyosa. Ésta fue construida como residencia de descanso en la década de 1880. En los trabajos arqueológicos fueron detectados los antiguos muros de la residencia. El material constructivo de dicha vivienda es de origen europeo, principalmente francés, exceptuando los ladrillos. Las lozas halladas en dicho lugar son todas de origen europeo fundamentalmente inglesas (88\%). En la Tabla 5 se resume la cantidad total de hallazgos. 


\begin{tabular}{|l|r|}
\hline Botones & 12 \\
\hline Otros & 120 \\
\hline Porcelanas & 23 \\
\hline Metales & 456 \\
\hline Vidrio & 347 \\
\hline Ceramica & 23 \\
\hline Lozas & 167 \\
\hline Gres & 12 \\
\hline Azulejos & 189 \\
\hline Materiales de Coastrucción & 987 \\
\hline Baldosas & 260 \\
\hline Liticos & 12 \\
\hline becos & 267 \\
\hline tevililes & 12 \\
\hline plastlcos & 34 \\
\hline Otros & 56 \\
\hline
\end{tabular}

Tabla 5

En el Sitio Rodríguez - Visillac fue descubierta una estructura de mediados del siglo XIX y anterior a la llegada del ferrocarril en 1857, esto queda en claro a partir de observar que los pisos de ladrillos tienen continuidad bajo de las vías del ferrocarril, con pisos de ladrillos y pórticos de quebracho, hasta el momento las lozas analizadas son de origen británico y además fueron hallados algunos fragmentos de mayólica de principio siglo XIX de origen español. También fue descubierta una moneda de un decimo de real 1822 de la provincia de Buenos Aires, dicha moneda fue acuñada en Gran Bretaña.

\section{Poniendo en relación los procesos históricos y arqueológicos}

A partir de las fuentes escritas podemos distinguir 5 períodos:

1. Inicio y desarrollo del territorio que luego formara el partido de San José de Flores (1588- 1806)

2. Inicios y desarrollo de San José de Flores (1806-1857)

3. Consolidación y explosión demográfica de San José de Flores (1857-1888)

4. Proceso de unificación a la Ciudad de Buenos Aires (1888 -1914)

5. Integración urbana a la ciudad de Buenos Aires (1914- presente)

En el primer período tal como sucedía con otros centros urbanos coloniales y europeos del período, la ciudad se encontraba rodeada por un cinturón de establecimientos productivos. El crecimiento de Buenos Aires como mercado consumidor abrió nuevas e interesantes posibilidades para la producción agropecuaria de su campaña más cercana. No es de extrañar, entonces, que desde tiempos virreinales la élite mercantil invirtiera en propiedades semirurales (Socolow, 1991). Este período se vincula con el Colonialismo clásico que Amin Samir (2001) caracteriza como el sometimiento de las sociedades americanas a través de la fuerza. A partir de la explotación de los recursos naturales de América en especial los minerales preciosos, se produce la acumulación originaria que permite el desarrollo del capitalismo (Frank 1978) (Dobb 2005). Buenos Aires era una pieza importante en la exportación del mineral de Plata extraída de Potosí. Además la ciudad porteña también se convierte proveedora de esclavos africanos al Ato Perú. Durante este proceso la ciudad pasa a ser un engranaje clave en la explotación minera de América por parte del imperio Español. Vale aclarar que la metrópoli se oponía a que la plata saliera por el puerto de Buenos Aires, por las presiones de la elite limeña, sin embargo por medio del comercio ilegal se escurría gran 
cantidad de plata a la vez que ingresaban esclavos y mercaderías de Europa vía Brasil. En 1615 Juan de Escobar afirmaba que gracias al intercambio Buenos Aires había prosperado "y han venido a vivir de asientos a ella muchas personas con sus mujeres e hijos y se han edificado muchas casas y poblado chacras, de que hay mucha labranza y crianza de ganados" (Garvich 1988).

El segundo período está caracterizado por el desarrollo mercantil y burocrático de Buenos Aires (comercio legal, semi legal, clandestino, administración y transporte). Esto esta fuertemente vinculado con el desarrollo de chacras y quintas para el abastecimiento de la ciudad. Una de las actividades principales era la actividad triguera, la dinámica de producción beneficiaba al que lograba concentrar las cosechas o poseía molienda propia (Ciliberto 2004). Los precios del trigo aumentan lenta pero constantemente. Esta etapa se vincula con el comienzo de la etapa del Imperialismo Clásico, donde hay rivalidades interimperiales donde se diputan la influencia sobre las semi-periferias y periferias (Samir 2001). El comercio internacional de Buenos Aires está dominado por el imperio británico, los productos industriales de este origen invaden el mercado interno. Mientras los cueros y el sebo son los productos de exportación de esta tierras. El imperio Británico para ese momento tiene la hegemonía del sistema mundial (Arrighi 1999), por lo que no es casual encontrar que el comercio en Buenos Aires en ese momento estaba manejado por los británicos, como ejemplo el Banco Provincia de Buenos Aires fundado en 1822, era presidido por el británico William Cartwright (Graham Yooll 2007), es una muestra cabal de ello.

El tercer período, se vincula con el desarrollo de nuevos medios de trasportes que aceleran la velocidad de traslado de las mercaderías y las personas desde Flores hacia Buenos Aires. La producción agrícola, sigue siendo muy importante para el abastecimiento de la ciudad, pero el casco urbano del Pueblo de San José de Flores se desarrolla y se consolida con gran velocidad. El valor de las tierras ubicadas en el sector periférico al pueblo comienzan a amentar paulatinamente con la llegada del ferrocarril y con la aparición posterior del tranvía se produce un verdadero boom de loteo de solares para la construcción de viviendas (Cunietti Ferrando 2006). Durante el final de este período se consolida el Estado Nación moderno, y el rol que ocupara la Argentina dentro del sistema mundial será el de productor agrícola ganadero (Girbal -Blacha 1997). A nivel planetario este período sigue hegemonizado por el imperio británico y se caracteriza por la dependencia de Latinoamérica por los capitales de los países centrales (Dos Santos 2003).

El cuarto período se caracteriza por el de la urbanización casi total del antiguo partido de San José de Flores, el aluvión migratorio que recibe la Ciudad de Buenos Aires es tan grande que la población del oeste porteño cuadriplicó su población entre 1904 y 1914, pasando de 104.000 a 456.000 habitantes, la población de la ciudad en tanto pasó de 951.000 a 1.575 .000 habitantes (Braun y Cacciatore 1996). La Argentina durante este período siguió caracterizándose como productora agrícola ganadera y compradora de productos industrializados, una economía altamente extranjerizada en los procesos claves como el transporte y los frigoríficos, sobre todo por capitales británicos, sin embrago la disputa interimperial también se desarrolla en la Argentina, y la hegemonía británica es disputada por Estados Unido (sobre todo) y Alemania.

El quinto período no es objeto de estudio de nuestro proyecto porque ya presenta una historia común con el resto de la ciudad de Buenos Aires. 
Desde el punto de vista del registro arqueológico podemos distinguir 4 periodos en San José de Flores:

1 Anterior a 1857 (Baja densidad de hallazgos), Solo tenemos algunos artefactos hallados bajo los pisos y bases de la estructura hallada en el terreno Rodriguez - Visillac (Una moneda y un fragmento de mayólica) y los dos fragmentos de lozas creamwere hallados en el Corralón de Floresta.

2 Anterior a 1890 (Densidad media de hallazgos), los artefactos que se vinculan a estos son los rescatados bajo los pizos y bases de las estructuras de la residencia de Murature, La Moyosa, se pudieron restos de lozas, vidrios, porcelanas. Tambien muchos de los artefactos de Rodriguez - Visillac, rescatados sobre la estructura se relacionan a esta cronología.

3 Anterior a 1911 (Densidad Media alta de hallazgos), los registros más importantes se vinculan con la capa de relleno del Corralón de Floresta, pero tambien entran en este período los de Nazca 313.

4 Anterior a 1930 (Densidad alta de hallazgos). Los registros arqueológicos vinculados a este momento, son los de una de las unidades de la Plaza Pueyrredón, los objetos rescatados durante las obras en el Corralón de Floresta, y muchos elementos rescatados sobre las estructuras de la Moyosa y el Muro de Rodriguez - Visillac.

El registro anterior a 1857 es muy escaso y sólo pudo ser hallado en un solo sitio (Rodríguez-Visillac). Fundamentalmente se compone de una estructura (pared y piso), restos de un pilar de madera (quebracho), una moneda de 1822 y algunos fragmentos cerámicos, y de lozas. Lo que se puede ver es que en este período los materiales de construcción son sencillos y de origen local, en su mayoría de Flores, salvo las maderas que provenían del Chaco pero ninguno de estos provenía de Europa. En cambio la moneda (un décimo de Real de la Provincia de Buenos Aires), y la ceramica provenian Europa. La moneda aunque era de circulación local estaba acuñada en Gran Bretaña, mientras que la cerámica tipo mayólica talavera es de origen español. En este momento se observa que Flores es un pueblo de campaña que necesita traer de otras localidades muchos productos, salvo los ladrillos, arenas y cal que se producían localmente (extraídos de los bañados del Riachuelo dentro del Partido). Las lozas halladas en el Corralón de Floresta que cronológicamente pertenecerian a este período son de origen británico. Mientras las maderas para construcción provenían de la región chaqueña. Y los productos industrializados provenían de Europa, centro del sistema mundial en especial Inglaterra (Arreghi 1999).

El segundo periodo arqueológico, está representado por hallazgos en el Sitio Moyosa, parte de los de Rodríguez - Visillac. En este período observamos abundantes restos de materiales de construcción extranjeros, sobre todo en la construcción de las estructuras de la que fueran la residencia del Dr. Murature, La Moyosa, todas las baldosas, tejas y azulejos son de origen francés (marcas Perre Maurel Abaugne, Pierre Sacoman y Havre) otros revestimientos son de origen británico, y las cañerías de desagüe son alemanas. Los únicos objetos de fabricación local son los ladrillos. En Rodriguez - Visillac también la mayoría de los materiales de construcción son de origen europeo, sobre todo francés. En cuanto al conjunto 
de las lozas son abundantes la de origen británico (88\%), seguidas por las francesas $(7 \%)$ y las belgas ( $4 \%$ ). Otro conjunto importante son fragmentos de botellas de gres, estas son todas de origen europeo en su mayoría británicas $(85 \%)$ seguidas por las alemanas $(15 \%)$, estas botellas eran utilizadas para la cervezas, ginebras y para las aguas carbonatadas. El registro material nos está mostrando una profunda dependencia de los productos industriales europeos, sobre todo británicos aunque en los materiales de construcción se ve el gusto de la elite local por lo francés. También se puede decir que este registro material es un reflejo de las disputas interimperiales (Mandel 1978, Arreghi 1999), cuando observamos los orígenes de los materiales industriales, obviamente que también denota la importancia británica en el economía argentina. Además se puede argumentar que la variedad de orígenes de los artefactos es producto de que Argentina en ese momento es un estado semiperiferico (Wallerstein, 1989) que su burguesía negocia con las distintas potencias imperiales sin ser controlado directamente por ninguno de ellos.

El tercer período que podemos distinguir en el registro arqueológico, tiene que ver ya con una integración casi total de Flores a la ciudad de Buenos Aires. Por eso la mayoría del registro son restos producidos en toda la ciudad y no exclusivamente en Flores. El sitio que mejor representa este período es el Corralón de Floresta, también la recolección de rescate de la Plaza Pueyrredón. Ambos sitios son un relleno que provenía de la incineración de residuos de la ciudad de Buenos Aires (Camino 2009) (Seguí y Turk 2009). El conjunto de las lozas son en su mayoría de origen británico $(85 \%)$ seguida por alemana $(7 \%)$ y francesa $(5 \%)$. El conjunto de los vidrios tiene un alto porcentaje de origen nacional (30\%), similar al de origen británico (33\%) y al de origen estadounidense (29\%) (Traba y Ansaldo 2009). El conjunto de materiales de construcción es dominado por tejas y baldosas de origen francés (100\%) (Hanela y Orsi 2010). En cuanto los restos estructurales presentes en el sitio Corralón de Floresta, grandes galpones de acero, conocemos el fabricante por el hallazgo de la placa que decía: “A \&J Main \& $C^{\circ} L^{\circ}$. 1909. Structural Engineers. Glasgow London \& Calcuta". Los restos materiales de estos sitios nos muestran que la Argentina sigue dependiendo de la industria del centro del sistema mundial, sin embargo comienza un lento crecimiento de la industria liviana como queda representado en el porcentaje de vidrio de industria nacional, esto está dado por el carácter semiperiferico del país en este momento del desarrollo del sistema mundial (Wallerstein 1989). Es interesante destacar cómo la grandes estructuras de acero son originarias del imperio británico (Kennedy 1987). Para este momento de desarrollo del sistema mundial vemos a la Argentina como productor de materias primas principalmente de origen agrícola, con una incipiente industria para cubrir el mercado interno y dependiente de la mayoría de los productos industriales fabricados en los países centrales o en las colonias formales de estos.

El cuarto período distinguido por la Arqueología en Flores, está íntegramente ligado a una unidad de excavación de la Plaza Puyrredón. Los restos materiales recuperados representan un sólo evento de descarte seguramente vinculado con una demolición y construcción en la plaza. Los materiales de construcción hallados, azulejos, baldosas, tejas, son en un $95 \%$ de origen nacional, y los ladrillos son todos de industria local. El conjunto vitreo está representado casi en su totalidad por productos de fabricación local (92\%). El conjunto de lozas también muestra un alto porcentaje de fabricación local $(70 \%)$, seguido por las de origen británico (25\%) (Mercuri et al. 2004b). En cuanto los restos de porcelanas son de origen japonés casi en su totalidad $(90 \%)$. En este período se observa un desarrollo avanzado de la industria liviana en el país, gracias al desarrollo del mercado interno y a una 
merma en las importaciones por la primera Guerra mundial. Esto sin embargo no quiere decir que el país no siga siendo principalmente un productor de materias primas y un importador de bienes manufacturados (sobre todo industria pesada). Igualmente el desarrollo industrial alcanzado en este momento pone a la Argentina (Schavarzer 1998) en una posición semiperiferica dentro del Sistema Mundial.

\section{Palabras Finales}

El Sistema Mundial es donde las distintas formaciones sociales interactúan, éste es complejo y no igualitario, esto implica la generación de distintos efectos en sus diferentes componentes (Frank y Gills 1993). En el caso de estudio (la sociedad de San José de Flores) se observaría la posición subordinada de esta sociedad con respecto a la economía europea en general y a la británica en particular. Otro aspecto fundamental es la dependencia del pueblo de Flores a la ciudad de Buenos Aires, puerto de entrada y de salida de todos los productos de la Cuenca del Plata.

La mayoría de los materiales del siglo XIX y principios del XX hallados en el registro arqueológico de Flores provenían de Europa, dato que muestra el grado de dependencia industrial de la economía argentina con las grandes potencias económicas de la época.

San José de Flores como ya se mencionó, se ubicó en un punto geográfico estratégico donde las características naturales de las tierras eran óptimas para el desarrollo de la agricultura, la horticultura y la fruticultura (Ciliberto 2004), además de encontrarse a la vera del Camino Real y a sólo una legua y media de Buenos Aires. Esta ventaja económica comparativa permitió el desarrollo de esta población. No obstante, la explotación de esta ventaja dependía del desarrollo de la ciudad de Buenos Aires. Ésta fue nombrada capital del nuevo Virreinato del Río de La Plata en 1776, lo que trajo aparejado el crecimiento de la población y paralelamente un gran desarrollo del comercio ilegal (Alonso 1999). Es en ese momento cuando Juan Diego Flores decide invertir una importante suma de dinero en la compra de las tierras que en el futuro serán el partido de San José de Flores. Gracias a las compra de estas tierras Flores amasó una fortuna con el arrendamiento y la producción directa de trigo y leña para el mercado de Buenos Aires.

El área de producción rural para el mercado de Buenos Aires parece ajustarse al geosistema propuesto por Johan Heinrich Von Thünen (1857) para la Europa del siglo XIX. El considera que una gran ciudad situada dentro de una gran planicie de fertilidad uniforme organizaría la producción agrícola según los costos del transporte y las características de la producción. Una agricultura racionalmente ejecutada las tierras más cercanas a la ciudad para los cultivos de gran peso o volumen con relación a su valor y aquellos que se consumen en estado fresco y a medida que nos alejamos del centro urbano la tierra deberá producir materiales de mayor valor y que requieren menor gasto de transporte.

Este contexto geoespacial se inicia el ascenso de la aldea fundada hacia fines del Siglo XVI en el margen del Río de La Plata. De marcado carácter mercantil desde sus comienzos, la misma se encuentra inserta en el Sistema Mundial en tres niveles, con la economía Minera de Potosí y el comercio por ésta generada (tanto legal, semilegal y clandestino), con Brasil y las costas de África a través de los contactos intercoloniales y con la metrópoli (Moutokias 1988). 
Posteriormente, la producción ganadera de la región pampeana fortaleció aún más el comercio internacional y fue delineando el perfil económico de la región y su inclusión en el sistema mundial. Luego, en la década de 1880, el perfil agrícola adquiere más importancia. Pero el lugar que ocupara Argentina en el Sistema Mundial no cambia sustancialmente, salvo por pequeños matices producto de los ciclos económicos largos de la economía internacional (Modelski 1987) (Goldstein 1988) . Argentina, dentro de este sistema, jugaba, y sigue jugando, el papel de productor de materias primas (Sebreli 1972, Sunkel 1976, Camino 2003).

El surgimiento y desarrollo de San José de Flores, aunque con dinámicas propias, debe ser entendido dentro de la dinámica del desarrollo del Sistema Mundial, desde área de aprovisionamiento de la Población de Buenos Aires hasta ser un barrio de esta ciudad. Si se analiza el registro arqueológico recuperado en el otrora pueblo, en forma aislada sin vincularlo a las dinámicas generales del sistema las conclusiones a las que se arribaran no tendrán fuerza explicativa que implica relacionarlo con el todo. Esto no implica perder de vistas las particularidades del lugar, como se expresó anteriormente cada sociedad se integra a al sistema mayor con sus particularidades y sus ventajas sistémicas (Camino 2008). El registro material de San José de Flores es claro en mostrarnos el fluido comercio con la metrópoli europea y con el puerto de Buenos Aires, esto gracias a las vías de comunicación en especial con la llegada del ferrocarril. Aún hoy se conservan varias construcciones inmediatamente posteriores a la llegada del ferrocarril al pueblo, y éstas muestran una característica especial, todas ellas tienen sus galerías con vista a las vías del ferrocarril ya que era ver pasar el progreso frente a sus hogares. Todo esto creemos que sustenta nuestra hipótesis de que la ubicación espacial del pueblo era estratégica, y que a partir del desarrollo de los nuevos medios de comunicación aumentó la escala de intercambio con Buenos Aires.

En este trabajo se pretendió mostrar los avances de investigación llevados a cabo en el marco del proyecto Prehistoria y período colonial Temprano en el origen de San José de Flores (Camino 2006), siendo un aporte a la Arqueología de las mega ciudades latinoamericanas.

\section{Agradecimientos}

A todo los que participan en el Proyecto Arqueológico Flores que sin ellos nada de esto sería posible: Silvina, Aniela, Diana, Sheila, Valeria, Eugenia, Florencia, Cristal, Federico, Juan Pablo, Ivan, Javier y Oscar. A Daniel Schavelzon por su apoyo permanente al proyecto. A Hernán Muscio por sus aportes teóricos. Al CONICET que si su financiamiento el proyecto no podría realizarse.

\section{Bibliografía citada}

Alonso G. F.

1999. Estudio del comercio de esclavos en el Río de la Plata. En La Ruta del Esclavo en el Río de la Plata. UNESCO Montevideo

Amin S.

2001. Capitalismo, imperialismo, mundialización. en Resistencias Mundiales, CLACSO, Buenos Aires 
Arrighi G.

1999. El largo siglo XX. Ed Akal. Barcelona

Braun, C y Cacciatore, J.

1996. Arquitectos Europeos y Buenos Aires, 1860-1940. Fundación TAU. Buenos Aires.

Camino, U. A.

2003. Consolidación de la República Liberal. Noticias de Antropología y Arqueología 2003, CD ROM Especial NAyA, Buenos Aires.

2004. El material cerámico de construcción en San José de Flores a fines del siglo XIX. Ponencia en IV Jornadas Arqueológicas Regionales. Chivilcoy, Buenos Aires.

2006. Prehistoria y período colonial temprano en el origen de San José de Flores. Proyecto Doctoral CONICET. Manuscrito en posesión del autor.

2007. Excavaciones arqueológicas en un corralón municipal del s XX. VI Jornadas de Arqueología de las Regiones Pampeana y Patagónica. UNMPL (ed.): CD. Mar del Plata, Argentina.

2008. San José de Flores paradas obligada desde y hacia Buenos Aires. Revista de arqueología histórica Argentina y Latinoamericana. Vol 2. Sociedad Argentina de Antropología.

2009. Rellenos Porteños. Revista de arqueología histórica Argentina y Latinoamericana. Vol 3. Sociedad Argentina de Antropología.

Camino, U y C. Mercuri

2005 Descubriendo la Plaza Pueyrredón: arqueología de rescate en Ciudad de Buenos Aires. Ponencia en XI Congreso Nacional de Arqueología Uruguaya, Salto.

Ciliberto, $\mathrm{V}$.

2004. Aspectos Sociodemográficos del crecimiento periurbano. San José de Flores (1815 - 1869). Ediciones Facultad de Humanidades. UNMPL. Mar del Plata, Provincia de Buenos Aires, Argentina.

Cunietti-Ferrando A.

1977. San José de Flores . El Pueblo y el Partido. (1580-1880). Junta de Estudios Históricos de San José de Flores, Buenos Aires.

2006. La Formación del Pueblo de Flores. El parcelamiento de las quintas grandes de Ramón Romero y Rodríguez Visillac, al norte de la Avenida Rivadavia. En: El Barrio de Flores en su Bicentenario 1906-2006. ED. Junta de Estudios Históricos de San José de Flores. Buenos Aires.

DobbM.

2005. Estudios sobre el desarrollo del capitalismos. Siglo XXI Editores. Buenos Aires.

Dos Santos, T.

2003. La teoría de la dependencia: balance y perspectivas. Plaza Janes Buenos Aires

Frank André G..

1978. World Accumulation 1492-1789. New York: Monthly Review Press; London:

Frank, A. G, y B.K Gills

1993. The World System. Five Hundred Years or Five Thousand?. Frank y Gills (eds.). Routledge, London, Gran Bretaña 
Garvich A.

1988. Los cristianos nuevos portugueses y la economía de la colonia. En 500 años de historia argentina. Tomo 3 Editorial Abril. Buenos Ares.

Girbal -Blacha, N. M.

1997. Agricultura y Ganadería (1914-1945). En Nueva historia de la Nación Argentina Vol 5. Academia Nacional de La Historia. Buenos Aires.

Goldstein, J.S.

1988. Long Cycles. Prosperity and War in the Modern Age. New Haven: Yale University Press.

Graham Yooll, A.

2007. La colonia olvidada. Tres siglos de habla inglesa en la Argentina. Emecé Editores Buenos Aires.

Hanela J. y Juan P. Orsi

2010. Materiales de Construcción adquiridos por las elites porteñas antes y después del Ferrocarril. Procesos de modificación y aumento en las construcciones en San José de Flores. En Actas Congreso Nacional de Arqueología XVII. Mendoza

Kennedy, P

1987. The Rise and Fall of the Great Powers. New York: Random House.

Lenin, $\mathrm{V}$.

2006. El imperialismo, fase superior del capitalismo. Quadrata Buenos Aires

López Borgoñoz, A.

1999. Modelos, Pasado, Sistemas Complejos y Sistema Mundial. II Congreso Penisunsular de Arqueología, Zamora. Vol. III. Universidad de Alcalá, España.

Mandel, E.

1978. El capitalismo tardío. ERA, México

McGlade, J.

1999. Arqueología, dinámica no lineal y discurso histórico. Trabajos de Prehistoria Vol. 56, $N^{o}$ 2,pp. 5-18

Mercuri, C, U. Camino y G. López,.

2004a.El primer ferrocarril y su impacto en San José de Flores, Primeras Aproximaciones. Miradas al pasado desde Chivilcoy. (CD- ROM). Centro de Estudios en Ciencias Sociales y Naturales de Chivilcoy CECH (ed.), Chivilcoy, Provincia de Buenos Aires, Argentina.

2004b. Informe relativo a los trabajos arqueológicos realizados en la Plaza Pueyrredón. Presentado en la Secretaría de Cultura de GCBA. Manuscrito en posesión de la DGPat, Gobierno de la Ciudad Autónoma de Buenos Aires

Modelski, G

1987. Long Cycles in World Politics. London: Macmillan. 
Moutakias, Z

1988. Contrabando y Control colonial en el siglo XVII. Bibliotecas Universitarias, Centro Editor de América Latina, Buenos Aires.

Pisano, P.

1976. Breve Historia de San José de Flores. Ediciones de la Junta Histórica de San José de Flores, Pub. N48, Buenos Aires.

Prignano, A.

1998. Crónicas de la Basura Porteña. Del fogón indígena al cinturón ecológico. Junta de Estudios Históricos de San José de Flores. Buenos Aires.

Schavarzer J.

1998. Nuevas perspectivas sobre el origen industrial argentinos (1880- 1930). www.imagomundi.com.ar

Sebreli J J.

1972. Apogeo y ocaso de los Anchorena. Ediciones Siglo Veinte. Buenos Aires.

Seguí Silvina T. y E. Turk

2009 Comparación de restos zooarqueológicos extraídos de los sitios "Corralón de Floresta" y "Plaza Flores", depositados por la incineración de residuos de la ciudad de Buenos Aires a finales del S. XIX y principios del S. XX. En: V Congreso Nacional de Arqueología Histórica. Universidad Nacional de Lujan. Prov. Bs. As.

Socolow, S.

1991. Los mercaderes del Buenos Aires virreinal: familia y comercio. Editorial La Flor. Buenos Aires.

Sunkel, O.

1976. La naturaleza de la dependencia Latinoamericana. En: América latina en la economía internacional. Urquidi V. L. Y Thorp R. comp. Fondo de Cultura Económica. México.

Thünen, J. H. V.

1857. Recherches sur l'influence que prix de grains, la richesse do sol et les impôts execent sur les sytèmes de cultura. Guillaumin et Cie, Paris.

Traba A. R. y J. M. Ansaldo

2009. En Buenos Aires no comen vidrio pero lo consumen. Una mirada a la vida porteña a finales del siglo XIX. En V Congreso Nacional de Arqueología Histórica. Universidad Nacional de Lujan. Prov. Bs. As.

Wallerstein I.

1974. The Modern World-System, Vol. 1, New York: Academic Books. 1988. The Modern Word System, Vol 3, New York: Academic Books.

1989. The West, capitalism, and the modern world-system. Prepared as a chapter in J Needham, Science and Civilization in China, Vol. 7: The Social Background, part 2. Select. 
